\title{
Dust Suppression on Open Pit Drill Rigs-Case Study from Skorpion Zinc Mine
}

\author{
Stefanus Andries Jakobus Potgieter ${ }^{1}$ and Johannes Jacobus Labuschagne du Plessis ${ }^{2}$ \\ 1. Skorpion Zinc Mine, Rosh Pinah, Namibia \\ 2. Department of Mining Engineering, Faculty of Engineering, Build Environment and Information Technology, University of \\ Pretoria, Pretoria 0028, South Africa
}

\begin{abstract}
Spotters and samplers around the drill rigs can be exposed to high dust concentrations. In this study it was found that individuals were exposed to as much as $14.2 \mathrm{mg} / \mathrm{m}^{3}$, which exceeds the OEL (Occupational Exposure Level) of $10 \mathrm{mg} / \mathrm{m}^{3}$ [1]. The work on which this paper is based included an extensive literature study, as well as field investigations. Number of additional dust suppression interventions was identified. These improvements, listed below, will assist in reducing dust concentrations around the drill rigs: Increase maintenance frequency on the shroud, sealing ring, suction pipes and filters of the drill rigs. Design and install new overlapping rubber belts on the shroud of the DM45. Install an air-blocking shelf on the inside perimeter of the shroud of the DM45. Install an airflow meter to ensure that the $Q_{\mathrm{C}}: Q_{\mathrm{B}}$ ratio never drops below 3:1. Only allow wet drilling. Flush the dust collector system more regularly with compressed air to ensure that it does not become blocked. Introduce stricter supervision to ensure that the suction pipes are always connected to the shroud. Give drill rig operators more advanced training to ensure more effective drilling in order to reduce dust levels.
\end{abstract}

Key words: Dust suppression, open pit mining, drilling.

\section{Introduction}

The mine studied uses drilling and blasting operations to break the rock. Loading and hauling then follows with a monthly production of 1.6 million tons. The pit is currently $160 \mathrm{~m}$ deep, $1,200 \mathrm{~m}$ long and 900 $m$ wide and will eventually reach a final depth of 310 $\mathrm{m}$. A bench height of $10 \mathrm{~m}$ is being utilized.

The mine's target is to drill 147 holes per day, which equates to a total of $1613 \mathrm{~m}$ per day. This target is achieved by employing the following drilling fleet:

- Three Atlas Copco Roc-L8s with down-the-hole hammers;

- One DM45 drill rig with a rotary tri-cone drill bit.

Excessive amounts of dust in or around the pit were reported by the blasting, geology, surveying and maintenance crews that work next to the blocks being

Corresponding author: Johannes Jacobus Labuschagne du Plessis, Ph.D., professor, research fields: dust control, coal mine explosion prevention and energy efficiency. drilled. The drill spotters and grade control operators working in the vicinity of the drilling area are, however, the most susceptible to the dust exposure, leading to potential respiratory diseases.

Although the drill rigs have dust suppression systems installed, the correct utilization and maintenance of these systems remains an area of concern and hence the need for this study.

An additional four drill rigs will arrive in the near future to the mine. The introduction of the new drill rigs will contribute to even higher dust levels in or around the open pit. To improve conditions around the drill rigs and reduce the potential exposure of workers it is important to determine the deficiencies of the dust suppression systems currently installed on the drill rigs. It is also important to determine the shortcomings in maintenance and operating procedures.

The drilling processes achieved by a combination of rotation, thrust, indexing and percussion of the drill bit [2]. All these forces allow the rock to be chipped and 
grinded at the contact between the drill bit and the rock. This is the site where dust is created and the bailing air carries these drill chippings and dust particles out of the hole and into the atmosphere. It is of vital importance to control the dust that escapes the drill collar to reduce the amount of dust escaping into the atmosphere.

\section{Suppression of Drilling Dust}

If not properly controlled, drilling operations may expose drill operators, drill helpers or often referred to as spotters, and grade control operators to large amounts of respirable dust. Controlling dust at the drill rigs can be achieved using a wet suppression system and/or a dry suppression system.

\subsection{Wet Drilling Dust Suppression}

The wet suppression system works by introducing water into the bailing air that is send down the drill stem. The water then mixes with the dust and drill chippings at the bottom of the drill hole where the dust is liberated. This allows the dust particles and drill chippings to stick to each other, making them less airborne as they are bailed out of the drill collar. Other than dust suppression, the advantage of using water in percussion drilling is an improvement in the penetration rate of drilling [3].

Tests have shown that wet drilling can reduce dust levels up to $96 \%[4,5]$. It is, however, critical that the drill operator ensure that the water flow rate entering the bailing air is correct. Although the flow rate can range from 3.8 to $7.6 \mathrm{l} / \mathrm{min}$, it depends on the type of drill rig, the geology and the moisture content of the rock being drilled [4]. At some sites it was found that the dust suppression efficiency could be increased by increasing the water flow from 0.8 to $2.3 \mathrm{l} / \mathrm{min}$. However, when a flow rate of $3.8 \mathrm{l} / \mathrm{min}$ was reached, operational problems were encountered. This was due to the drill chippings becoming too heavy to be removed by the bailing air; they started to plug the drill bit and bind the drill stem [3,4]. It is therefore required that the drill operator adjust the water flow rate until the maximum amount of dust is being suppressed without encountering operational problems with too much water.

There are, however, disadvantages to using water with rotary drilling. Water can reduce the life of tri-cone roller bits by $50 \%$ or more $[4,5]$. This deterioration of the drill bits can be prevented by using a water separator sub. The sub is connected between the drill bit and the following drill stem, and separates the water from the bailing air. This is achieved by forcing the bailing air through sharp turns where the water separates from the air due to the inertia of the water being higher than that of the air. The compressed air then continues to the drill bit without containing water. When the water has built up to a certain level in the water reservoir, it escapes the water separator sub through the weep holes directly into the annulus above the drill bit. The water then mixes with the drill chippings and dust particles as it moves up the annulus. This prevents the water from moving through the drill bit and over the surface where the actual drilling action takes place. This is illustrated in Fig. 1. It was noted that dust reduction was improved from $96 \%$ to $98 \%$ when a water separator sub was introduced $[3,5]$.

\subsection{Dry Drilling Dust Suppression}

Dry drilling dust control systems can be up to $99 \%$ efficient if properly maintained [3, 4]. Dust particles and drill chippings escape from the drill collar with the aid of the bailing air and are contained within the drill deck and shroud. The dust collector system establishes a negative pressure within the shroud and draws the dust particles into the dust collector system. The dust collector system is composed of the fan exhaust, which creates the negative pressure, and the filters, which separate the dust from the air. Most filtering systems are self-cleaning. They use regular pulses of compressed air to remove the dust from the filter surface, and allow the dust to drop through the 


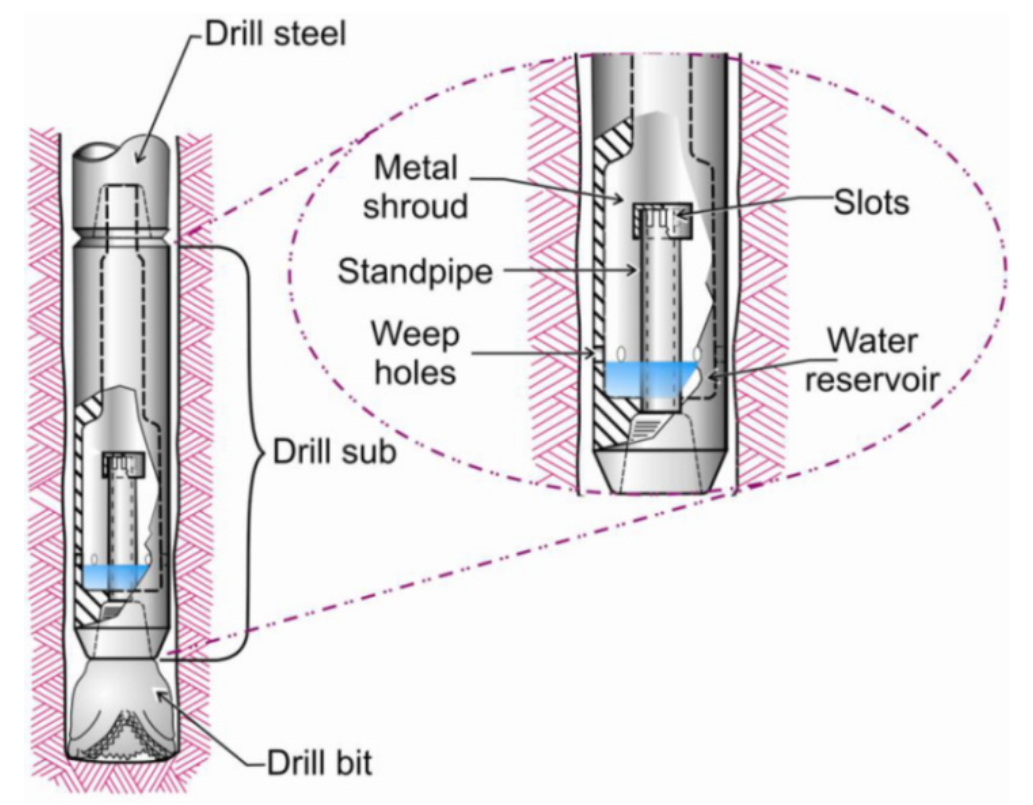

Fig. 1 Water separator sub-assembly [3].

bottom of the collector and onto the ground [3]. An additional cyclone may also be installed between the drill deck and the filters.

In order to maintain an adequate negative pressure inside the shroud it is important to have the correct drill deck and shroud design. Most shrouds are rectangular in design with four separate rubber belts suspended from the drill deck. Leakages often occur at these corners. It is therefore necessary to install angle-shaped corner flaps at these corners to create an overlap with the suspended rubber belts. Another solution is to make use of a single rubber belt installed along the perimeter of the drill deck.

A modification that can be made to the shroud design is to introduce an air-blocking shelf. This is composed of a $150 \mathrm{~mm}$ wide shelf installed along the inside perimeter of the shroud. An air-blocking shelf is shown in Fig. 2.

The bailing air containing the dust particles moves out of the drill collar along the drill stem until it hits the drill deck and disperses sideways due to the Coanda effect $[3,6,7]$.

The air then moves down the shroud walls and eventually strikes the ground, where the dust can escape to the atmosphere through the shroud gap. By installing an air-blocking shelf, the flow of air within the shroud is circulated within the top half of the shroud, giving the exhaust fan enough time to extract the dust. This reduces the possibility of the dust escaping through the gap below the shroud. The flow of air in the shroud and the effect of the air-blocking shelf can be seen in Fig. 3. It was reported in a study by Potts and Reed [8] that dust levels were reduced to between 66 and $81 \%$ after an air-blocking shelf had been installed. It should be noted that the air-blocking shelf becomes less effective when there is very little dust emission in the first place before the shelf is installed.

An additional indicator to determine the performance of the dust collector system is the ratio of its collector to the bailing airflow [3]. This can be expressed as $Q_{\mathrm{C}}: Q_{\mathrm{B}}$, where $Q_{\mathrm{C}}$ is the volumetric flow rate of the dust collector fan and $Q_{\mathrm{B}}$ is the volumetric flow rate of the bailing air that escapes out of the drill collar. Normal operating drills usually have ratios of 2:1 and this can be even as high as 3:1. During field observations it was noted that in some instances, due to poor maintenance, incorrect compressor settings, etc., the ratio may even drop below 1:1, rendering the dust collector system completely ineffective. It can be 


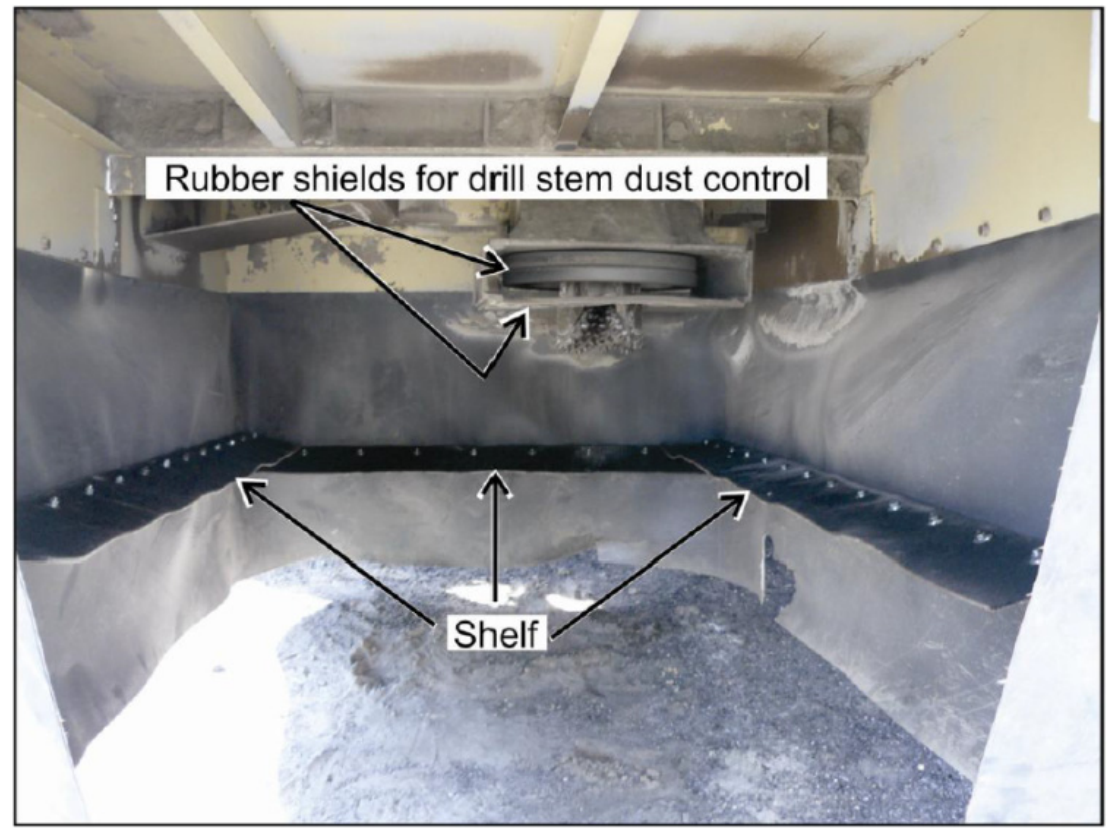

Fig. 2 Air-blocking shelf installed along the inside perimeter of the shroud [3].

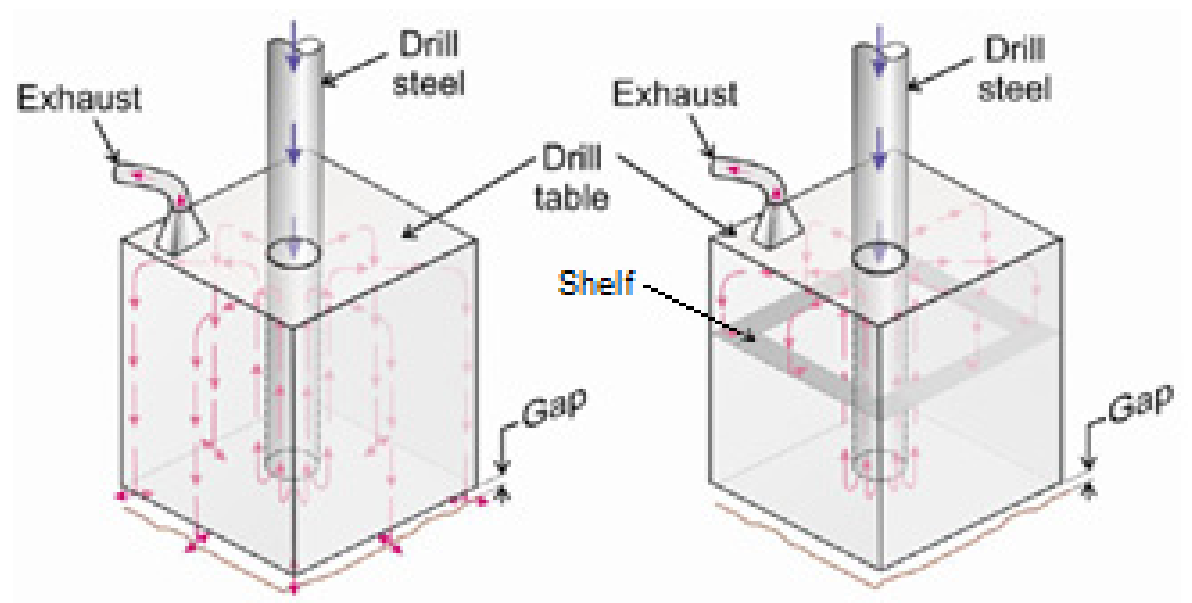

Fig. 3 Airflow model within the shroud without and with the air-blocking shelf [3].

seen from Fig. 4 that an increase in this ratio reduces the dust concentration, making the dust collector system more effective.

It should also be noted from Fig. 4 that a decrease in the gap between the bottom of the shroud and the ground will also reduce the dust concentration, thereby increasing the effectiveness of the dust collector system.

The dust that drops from the collector dump cyclone/filter may account for up to $40 \%$ of the respirable dust emissions of a drill rig [3,9]. The bottom of the dust collector dump point (cyclone/filter underflow) is on average between 60 and $90 \mathrm{~cm}$ from the ground. At that height the respirable dust escapes into the atmosphere when it falls through the air and when it hits the ground. It is therefore, necessary to install a brattice cloth on the underflow of the cyclone/filter with the aid of large hose clamp. This allows most of the dust particles to settle onto the dump pile. A study to quantify the effect of the installation of this brattice showed that it reduces the respirable dust level by between 63 and $88 \%[3,10]$. The efficiency is, however, dependent on wind speed and direction. The advantage of this brattice is that it is cheap and quick to install. 


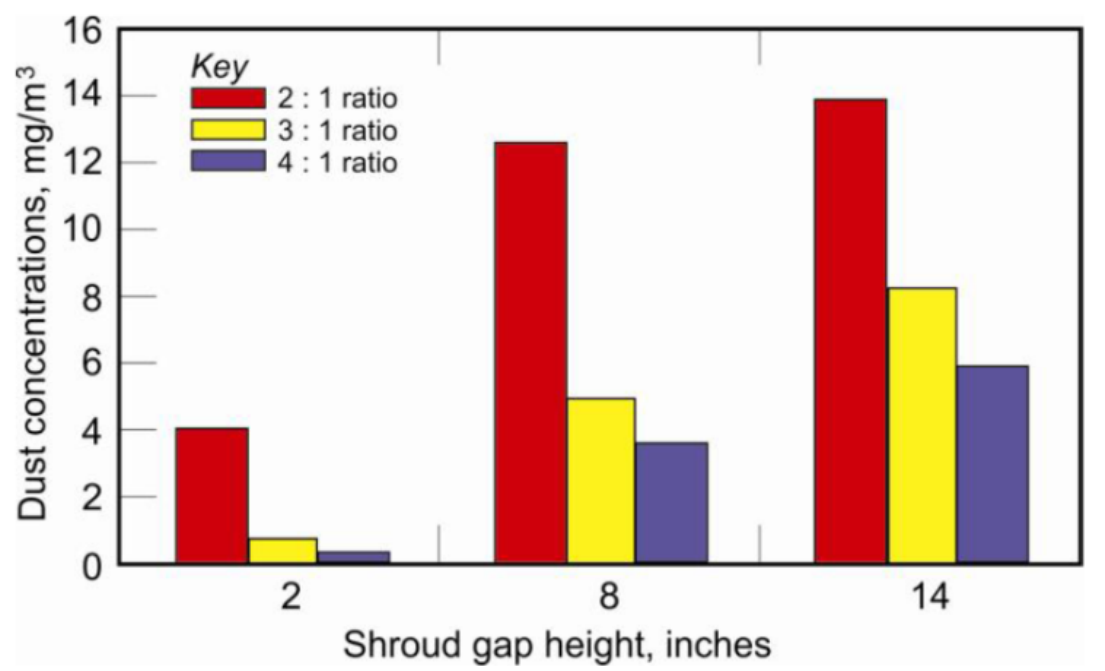

Fig. 4 Effect of different shroud gap heights at various dust collectors to bailing air ratios [3].

\section{Drilling Results and Discussions}

Dust pumps with pre-weighed filters $[11,12]$ were used to measure dust concentrations in various stationary working areas (environmental samples) and on various personnel (personal exposure) during the normal work shift.

The results from the measurements are shown in Table 1. Two of the spotters and samplers around the drill rigs were exposed to dust concentrations above the OEL $\left(10 \mathrm{mg} / \mathrm{m}^{3}\right)$ [1]. The potential over exposure of employees is a major concern as these employees may contract respiratory diseases over time.

\subsection{DM45 Drill Rig}

It was observed that large amounts of dust escaped from the bush that acts as a sealing ring where the drill stem enters the drill deck (see Fig. 5). After investigation it was revealed that the escaping dust was a result of poor maintenance. It must be emphasized that it is necessary to replace the sealing ring more regularly by following the correct installation procedures.

It can be seen from Fig. 6 that there are separate rubber belts hanging from the drill deck with open slits between them. Holes and cuts were also present in these hanging rubber belts. Additional open slits were also present at the corners of the shroud. All these slits, voids and holes cause the vacuum pressure to drop within the shroud, causing the dust to escape through these openings and into the atmosphere. It is therefore recommended that new rubber belts that overlap each other be installed, as well as angled rubber belts at the corners of the shroud. This will seal the shroud and ensure a higher negative pressure inside the shroud, thereby reducing the amount of dust escaping from the shroud. It is also recommended that regular maintenance be done on the shroud to ensure that there are no holes, cuts or open voids in the rubber belts.

It was realized that there was no air-blocking shelf on the inside of the shroud. It is therefore recommended that a $150 \mathrm{~mm}$-wide rubber belt be installed along the inside perimeter of the shroud that will act as an air-blocking shelf. The shelf should be installed half-way up the shroud and can be fastened to the sides of the shroud with angle iron, nuts, bolts and washers. This will allow most of the dust to circulate in the upper section of the shroud, to be extracted through the dust collector system.

It was unfortunately not possible to measure the volume flow rate of the dust collector extractor fan due to the mine not owning the equipment required to measure the airflow rate. It is therefore, recommended that a vane anemometer, wire anemometer or Pitot 
Table 1 Dust sampling results.

\begin{tabular}{lll}
\hline Location/ Activity & Type of test & Results $\left(\mathrm{mg} / \mathrm{m}^{3}\right)$ \\
\hline Spotters and samplers & Personnel & 14.10 \\
Spotters and samplers & Personnel & 5.66 \\
DR 04 drilling & Environmental & 8.32 \\
Roc-L8 & Environmental & 3.04 \\
Roc-L8 & Personnel & 0.21 \\
Geology pit area & Environmental & 0.39 \\
Drill rig training & Personnel & 1.62 \\
Spotters and samplers & Personnel & 4.31 \\
Spotting at DR-02 & Personnel & 14.20 \\
DR-02 & Environmental & 2.52 \\
\hline
\end{tabular}

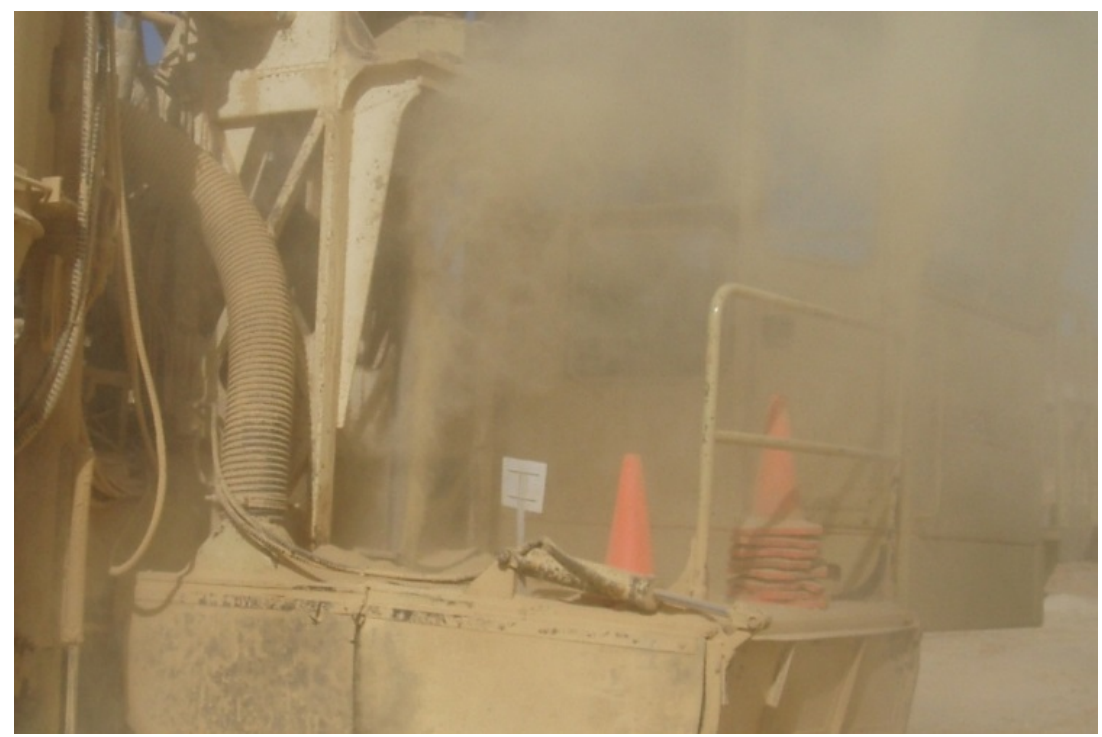

Fig. 5 Dust escaping the sealing ring where the drill stem enters the drill deck.

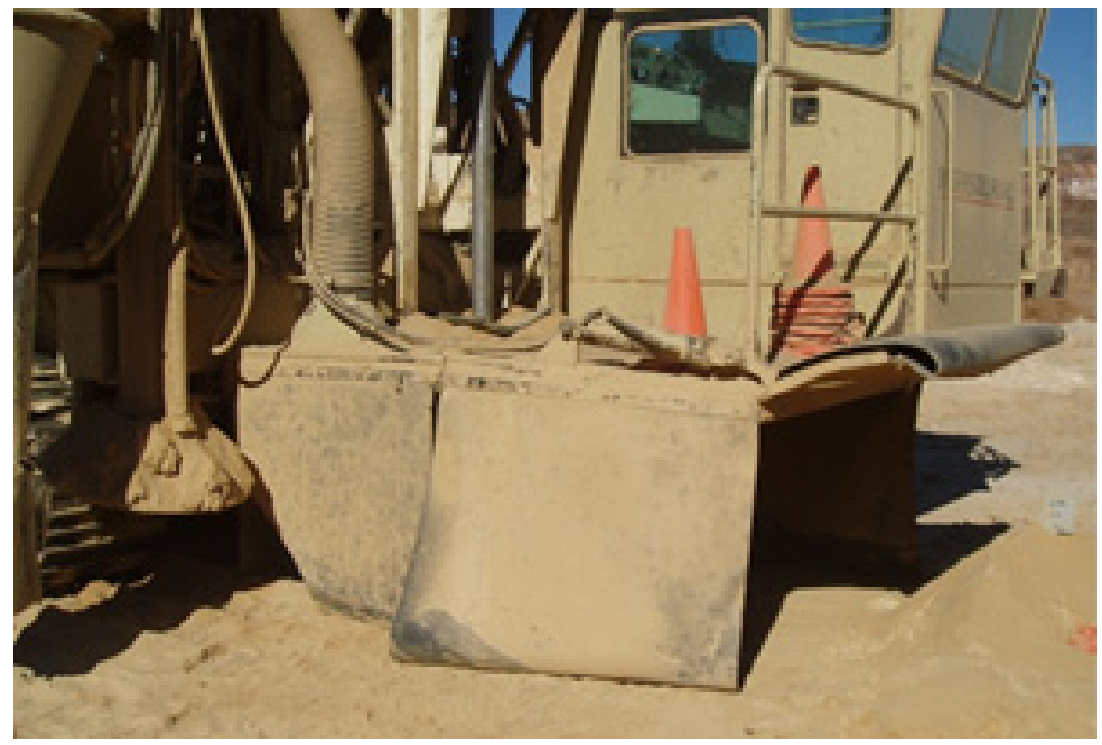

Fig. 6 Open slits between rubber belts of the shroud. 


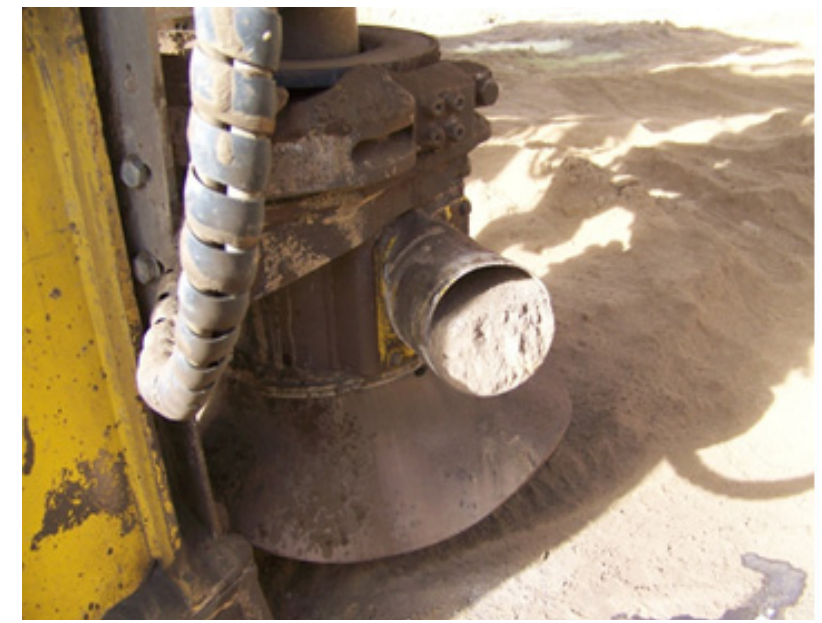

Fig. 7 Blocked dust collector pipe between shroud and cyclone.

tube be acquired in order to make regular collector flow rate readings at the drill rigs. This will enable the mine to know when to do maintenance on the dust collector system or when to change air flow settings if the $Q_{\mathrm{C}}: Q_{\mathrm{B}}$ ratio drops below $3: 1$.

\subsection{Roc-L8 Drill Rigs}

It was noted that drill operators only use water during drilling when the holes are collapsing to stabilize the sidewalls. Drilling while introducing water into the bailing air is one of the most effective ways to reduce dust levels. It is therefore, recommended that wet drilling practices be considered by operators, even if the sidewalls are stable.

Similar to the DM45 drill rig, large amounts of dust passed through the sealing ring where the drill stem enters the shroud. It is therefore recommended that the sealing ring be replaced more often following the correct standard maintenance procedures.

The drill operators often do not flush the dust collector system while drilling. This blocks the suction pipe between the shroud and the cyclone (see Fig. 7). Blockages in the suction pipe prevent the dust collector system from drawing the dust out of the shroud, causing the dust to escape into the atmosphere. It is therefore recommended that the drill operators flush the dust collector system more regularly by relieving the pull-down pressure and increasing the flow of the bailing air. In addition, the drill operators,

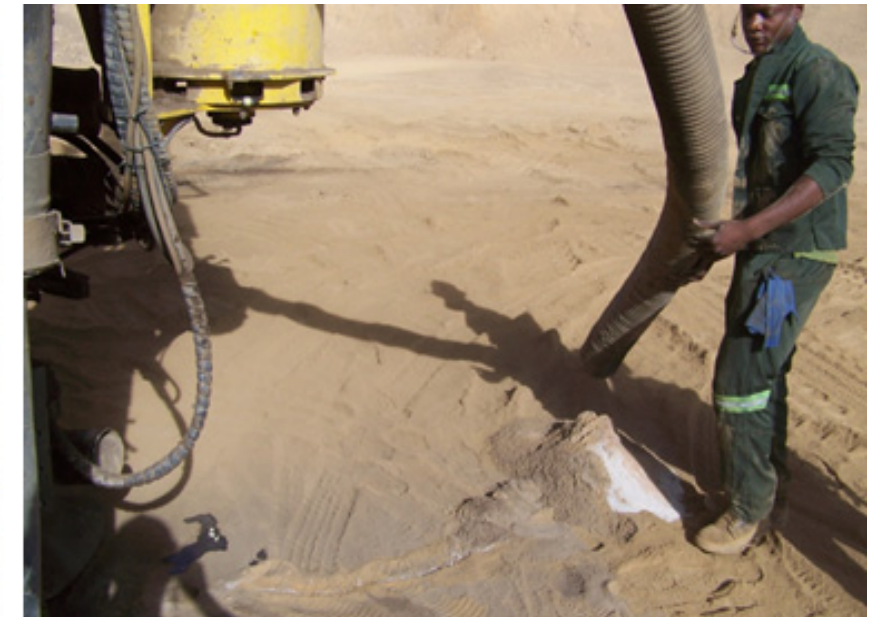

assistants, spotters or grade controllers often remove the suction pipe from the shroud to prevent blockages from occurring in order to reduce downtime and to increase production. This creates excessive amounts of dust and it is therefore recommended that stricter supervision be exercised. The supervisor should ensure that the drill operators flush the dust collector system more regularly and that the suction pipe is always connected to the shroud.

It was also realized that the dust collector pipes are susceptible to bending, which will causes a higher airflow resistance in the suction pipes. If the flow rate is reduced, the dust collector system will be less effective and more dust will escape into the atmosphere at the shroud. It is therefore recommended that regular maintenance be done on the suction pipes to ensure that they are whole, have no bends, and are tightly fastened to the remaining components (shroud, cyclone and filters). Large amounts of dust were also coupled with bad drilling practices. More dust was liberated when the drill chippings were very fine and less dust was observed when the drill chippings were larger in size. Inexperienced drill operators use excessive amounts of rotational pressure compared with the pull down pressure on the drill bit. This prevents the tungsten carbide teeth from indenting into the rock, and causes the drill bit to grind the host rock. The grinding action at the drill bit creates excessive amounts of fine drill chippings which become 
airborne much more easily when they are bailed out of the drill collar. It is therefore recommended that drill operators be trained to drill correctly and more efficiently. This will not only reduce dust levels, but also increase the drill bit life.

\section{Conclusions}

The dust concentrations reported from the sampling measurements on the mine indicated that spotters and samplers around the drill rigs are exposed to dust levels above the standard set for the OEL.

From the field investigation it was found that maintenance on the dust collector systems of the drill rigs was not being done to acceptable standards. More regular maintenance is required on the shroud, suction pipes, filters, and especially the sealing ring (where the drill stem enters the shroud) of the drill rigs. It was also recommended that new overlapping rubber belts be installed on the shroud of the DM45, as well as an air-blocking shelf on the inside perimeter of the shroud.

The mine needs to purchase and install an airflow meter to ensure that the $Q_{\mathrm{C}}: Q_{\mathrm{B}}$ ratio never drops below $3: 1$.

The drill operators should be required always to drill with water and to the flush the dust collector system more frequently to prevent any blockages in the suction pipes. Improved and advanced training for the drill operators is required. This will improve drilling practices, which will lead to reduced dust levels and increased drill bit life.

The implementation of the recommended improvements in engineering controls, better maintenance practices and better operating practices will assist in preventing any potential respiratory diseases and the degradation of the surrounding environment.

\section{References}

[1] Government Gazette of the Republic of Namibia. Labour
Act, 1992. Regulations Relating to the Health and Safety of Employees at Work. Schedule 1(2), Occupational Exposure Limits for Airborne Hazardous Substances Made under the Labour Act 1992 (Act 6 of 1992), (section 101, regulation 185 (1)).

[2] Kahramana, S., Bilginb, N., and Feridunoglub, C. 2003. "Dominant Rock Properties Affecting the Penetration Rate of Percussive Drills." International Journal of Rock Mechanics \& Mining Sciences 40: 711-23.

[3] Cecala, A. B., O’Brien, A. D., Colinet, J. S. J. F., Fox, W. R., Franta, R. J., Reed, R., Wm, J. J., Reeser, P. W., Rounds, J. R., and Schultz, M. J. 2012. "Dust Control Handbook for Industrial Minerals Mining and Processing." Department of Health and Human Services. Enters for Disease Control and Prevention. National Institute for Occupational Safety and Health. Office of Mine Safety and Health Research. Pittsburgh, PA, Spokane, WA.

[4] Page, S. J. 1987. Optimizing Dust Control on Surface Coal Mine Drills. U.S. Department of the Interior, Bureau of Mines Technology News 286.

[5] Page, S. J. 1991. "Respirable Dust Control on Overburden Drills at Surface Mines. Coal Mining Technology, Economics, and Policy." In Session Papers from the American Mining Congress Coal Convention, Pittsburgh, Pennsylvania, 523-39.

[6] Potts, J. D., and Reed, W. R. 2008. "Horizontal Air Blocking Shelf Reduces Dust Leakage from Surface Drill Shroud." Transactions of the Society of Mining, Metallurgy, and Exploration 324: 55-60.

[7] Reed, W. R., and Potts, J. D. 2009. "Improved Drill Shroud Capture of Respirable Dust Utilizing Air Nozzles Underneath the Drill Deck." Transactions of the Society of Mining, Metallurgy, and Exploration 326: 1-9.

[8] Potts, J. D., and Reed, W. R. 2010. "Field Evaluation of Air-Blocking Shelf for Dust Control on Blasthole Drills." Submitted to Mining Engineering.

[9] Maksimovic, S. D., and Page, S. J. 1985. "Quartz Dust Sources during Overburden Drilling at Surface Coal Mines." U.S. Department of the Interior, Bureau of Mines Informational Circular 9056.

[10] Reed, W. R., Organiscak, J. A., and Page, S. J. 2004. "New Approach Controls Dust at the Collector Dump Point." Coal Age, 20-2.

[11] NIOSH Manual of Analytical Methods (NMAM). 1994. Fourth Edition, Particulates not Otherwise Regulated. Total: Method 0500, Issue 2.

[12] Clere, J., Hearl, F., and NIOSH/DRDS. 1994. NIOSH Manual of Analytical Methods (NMAM), 4th ed. 